\title{
WILLFUL IGNORANCE AS RESISTANCE, HARM REDUCTION WORKERS AND RULING RELATIONS
}

by

Christopher Maxim Piercey Dalton, BA, BSW, Carleton University, 2010, 2015

\author{
An MRP \\ presented to Ryerson University \\ in partial fulfillment of the \\ requirements for the degree of \\ Master of Social Work \\ in the Program of \\ Social Work
}

Toronto, Ontario, Canada, 2017

(C) Christopher Dalton 2017 


\section{AUTHOR'S DECLARATION FOR ELECTRONIC SUBMISSION OF A MRP}

I hereby declare that I am the sole author of this MRP. This is a true copy of the MRP, including any required final revisions.

I authorize Ryerson University to lend this MRP to other institutions or individuals for the purpose of scholarly research

I further authorize Ryerson University to reproduce this MRP by photocopying or by other means, in total or in part, at the request of other institutions or individuals for the purpose of scholarly research.

I understand that my MRP may be made electronically available to the public. 


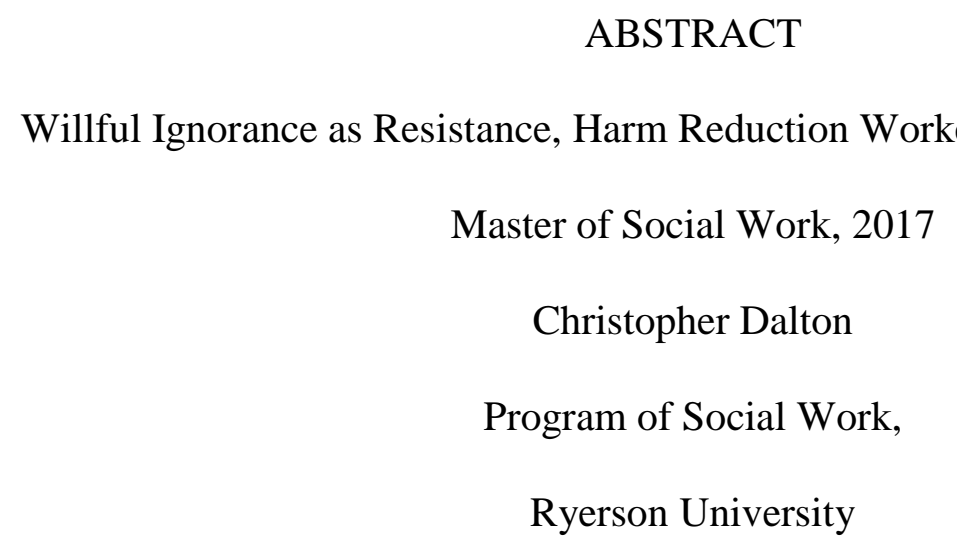

This paper will explore how front-line harm reduction workers govern the space of agency services. In order to study how this is done this writer completed an institutional ethnography to illuminate how power operates in the day-to-day practice of a harm reduction agency. Harm reduction services have been criticized as a site of neoliberal governance through risk-management. This study aims to explore how harm reduction workers perform and understand their role within their agency. This writer interviewed front-line staff members that distribute harm reduction material, asking them about their adherence to their organizational policies and procedures. The policies represented by the text of the signage within agencies was also analyzed. Study results showed that staff members used wilful ignorance to allow people to use drugs on agency premises, provided they did so in a discreet manner. Harm reduction workers also tried to reduce the suffering, and promote the larger political goals of harm reduction, to help people who use drugs. 


\section{TABLE OF CONTENTS}

Chapter 1: Introduction..................................................

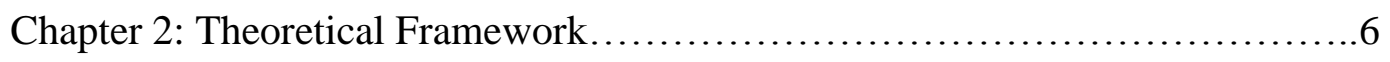

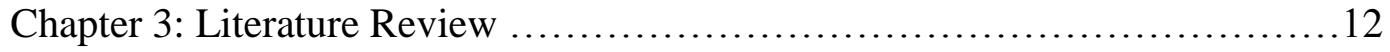

Chapter 4: Methodology.............................................21

Chapter 5: Findings................................................ 26

Chapter 6: Analysis/Discussion.......................................... 38

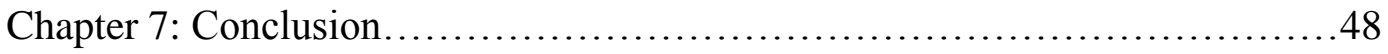

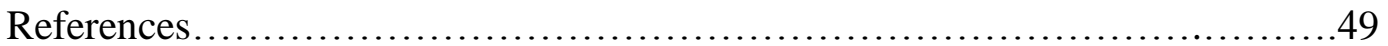




\section{Chapter 1: Introduction}

Canada's first supervised injection facility, Insite in Vancouver, reduced overdose deaths, curtailed rates of infectious disease, and decreased public drug use (Kerr, Wood, Montaner, \& Tyndall, 2009). As such, Insite has set a precedent for other Canadian cities to open their own supervised injection service (SIS). The municipal government of Toronto, the Ontario provincial government, and federal government have all voiced support for the creation of SISs (Duffy, 2016; McKeown, 2016). At these services, people can legally inject their illicit drugs under medical supervision with sterile equipment (Enns et al., 2016). Three injection sites have received federal government approval and will be opened in Toronto, at South Riverdale Community Health Centre (SRCHC), Parkdale Queen West Community Health Centre (PQWCHC), and 'The Works' at Toronto Public Health (TPH) (McKeown, 2016). In Ottawa, two sites have applied for a federal exemption, Sandy Hill Community Health Centre, which has been approved, and Somerset West Community Health Centre (Murray, 2017). While being closer to opening multiple SISs in Ontario, these are 5 agencies of 180 organizations in Ontario that are all currently distributing harm reduction supplies for people to inject and inhale drugs; however, none of these organizations are providing a space to do this.

At a policy level, the question of whether or not to support drug use in these settings is a complex issue requiring a balance between the legality of what is and is not legal for the person and the agency, the safety and well-being of the person using the drugs and the safety of other people in the same space. The recent overdose crisis in British Columbia led to front line workers opening safer injection sites, named overdose prevention sites, without federal approval (Brend, 2016). As this paper was being written, 
front line harm reduction workers opened overdose prevention sites in Toronto and Ottawa, Ontario (CTVNews.ca staff, 2017). This came as a result of workers witnessing too many overdose deaths that could have been prevented if there were operational supervised injection sites.

The Controlled Drug and Substances Act (CDSA) is a Canadian federal law that regulates drugs and substances. The CDSA has a clause in Section 56 where it can provide an exemption to organizations that wish to open supervised injection services. Without this exemption, illicit substances are illegal to possess and people who use drugs (hereafter referred to as PWUD) face criminal conviction if found in possession of these substances.

The problem of illegality of drug use began in Canada in 1908 with the passage of The Opiate Act. This act made the sale of opiates and cocaine, both of which had formerly been sold as medicines, illegal. The name of the act changed over the years and in 1996 it became the Controlled Drug and Substances Act (CDSA) (1996 c. 19). The history of drug prohibition in North America is rooted in racism (Khenti, 2014). Clifford (1992) illuminates how the early drug laws were implemented in the USA during times of slower economic growth, when unemployment was rising,

Chinese immigrants represented a labour force surplus and a threat to White, American citizens, they became victims of extreme prejudice. Opium smoking, a long time practice associated with the Chinese, began to be viewed as the means by which the Chinese would undermine American society (p. 310). White people were galvanized to feel their employment was threatened by "foreigners" Racist myths, namely that Chinese Opium was used to seduce White women; and Black 
men who used cocaine were dangerous and could not be stopped with bullets, were used to pass the prohibitory Harrison Act in 1914 in the USA (Clifford, 1992). The drugs themselves were not being seen as inherently harmful, although addiction was a problem. Instead, the disproportionate legal response to drugs on Chinese-Americans and Blacks illuminated the true purpose of the Harrison Act as an institutional form of racism.

By the 1960's a 'war on drugs' was declared which coincided with increased incarceration rates of Black and Hispanic people in the USA, scapegoating these communities (Friedman, 1998). Friedman (1998) describes how "poor people, working people, racial/ethnic minorities, and neighbourhoods can be divided and distracted by the politics of drug wars. Local users get blamed for individual and collective problems" (p.25). This criminalization of drug use can result in marginalized communities becoming more divided and restricting their ability to see past the problems of addiction that may affect people differently within their communities. In Canada, the war on drugs reflected the

political preferences for funding policing and prisons rather than social welfare and drug treatment. In 1992, enhanced law enforcement at both federal and provincial levels received $\$ 400$ million in funding; in contrast, financial support for treatment services was about $\$ 88$ million (Khenti, 2014, p. 192).

The disproportionate targeting of Black and Indigenous people in the war on drugs results in exacerbated poverty in groups that already are at a structural disadvantage due to white supremacy and colonialism (Khenti, 2014).

This war on drugs has resulted in a war on people who use drugs, creating what Moore (2007) calls a "criminal addict" where the mental health problem of the addiction 
is criminalized. Supportive social services are in place to help PWUD; however, the mere possession of illegal substances makes them criminals. The criminal justice system regulates these criminals by requiring them to attend addiction treatment, through actual drug treatment courts, bail conditions, or parole/probation conditions that require abstinence from drug use, thus their addiction is criminalized (Moore, 2007). PWUD are thus regulated by the risk they pose to themselves and others (Mugford, 1999).

It is important to examine the role that harm reduction services play in regulating this criminal addict. Harm reduction, which was created as a grassroots method to help people survive the harms of drug prohibition, has been professionalized and as a result, operates within a system of governance (Roe, 2005). Social work with its roots in social justice has embraced harm reduction; however, this professionalized harm reduction is focused more on risk management than the alleviation of suffering. Agency workers then become enforcers of drug prohibition laws, under the auspices of a supportive message of 'reducing harm'. Thus, as they are required to by law, harm reduction services are upholding drug-prohibitionist policies. Social workers then end up reinforcing the same prohibitionist policies that their services claim to resist. When they give PWUD harm reduction supplies and create a safe, non-judgemental environment, but do not provide an actual space to inject or smoke, social workers disproportionately affect the most marginalized PWUD, those who are homeless, or otherwise do not have a space to use drugs.

It is important to understand how social workers operate within their role as a harm reduction worker, how they abide by the rules of the agency they work for and how they resist. I am interested in how the social worker justifies their behaviour to enact their 
power onto their service users. Social workers have a long history of translating state power onto vulnerable populations, reinforcing the larger societal norms and expectations even when those norms are creating more harm to those populations. Given the current overdose crisis and the harmful war on drugs, it is important to understand how social workers contribute to or resist translating these larger societal expectations, thus either exacerbating the harms or curbing them.

The methodology chosen to study this process is Institutional Ethnography. The theoretical perspective taken from this paper is Michel Foucault's framework of governmentality. It will frame the social worker's actions as either implementing or resisting the policies of the CDSA. The first section will explain the framework of governmentality and how it has been applied to harm reduction, regulation of drugs and drug users. Next drug use space regulation and social worker's roles in following or resisting rules will be examined in a literature review. The methodology section will then describe why using institutional ethnography is the best method for studying this topic, and will give examples of how it has been used to study social work in other workplaces.

The subsequent findings section will illuminate how harm reduction distribution agencies operate, the messaging on their signs, and how harm reduction workers resist monitoring and encourage discreet drug use in their washrooms. The analysis section will then set the findings against the backdrop of research that has been mentioned in the literature review, and frames the findings within the concept of governmentality. Finally, the discussion will cover the implications for anti-oppressive practice and suggest future resistance strategies for harm reduction organizations. 


\section{Chapter 2: Theoretical Framework}

This chapter will explain the theoretical framework, provide the rationale for the framework, describe how others have used this framework in the area of drugs and harm reduction, and explain how governmentality fits into the methodology of institutional ethnography.

Michel Foucault described government as "an activity that undertakes to conduct individuals throughout their lives by placing them under the authority of a guide responsible for what they do and for what happens to them" (Foucault 1997, p. 68 as cited in Rose, O’Malley \& Valverde, 2006, p. 83). Governmentality was "understood in the broad sense of techniques and procedures for directing human behaviour. Government of children, government of souls and consciences, government of a household, of a state, or of oneself' (Foucault 1997, p. 82 as cited in Rose, O'Malley \& Valverde, 2006). Rose, O’Malley and Valverde (2006) took up governmentality from Foucault and said that in order to understand how we are governed in the present we must look to the "minor professions" that, they argued, reproduce governance. These are "the accountants and insurers, the managers and psychologists, in the mundane business of governing everyday economic and social life,” (Rose, O’Malley \& Valverde, 2006, p. 101). For the purposes of this research, I will focus on the minor profession of social work, specifically harm reduction equipment distribution workers.

I use governmentality as a concept to frame how social workers are practicing harm reduction in their day-to-day employment. Social workers' actions are governed by policies and procedures as well as the social work code of ethics. These policies are generally in-line with provincial and federal law. The CDSA is, for the most part, a 
policy of drug prohibition, that regulates which drugs and substances are allowed to be used, and in what circumstances. The drugs controlled by the CDSA are vast; the most commonly known of these drugs are heroin, cocaine, crack-cocaine, crystal meth, ecstasy, LSD, psychedelic mushrooms, and marijuana. Social workers in the harm reduction field play a unique role in regulating the people who use these drugs. As Pollack (2010) explained, "the profession of social work occupies an intermediary space, charged with 'translating' state power to individuals, families, groups and communities" (p.1264). State power from the federal level is translated down to the frontline social worker who is responsible for reinforcing the governing behaviour while providing a supportive atmosphere in their day-to-day work. The origins of harm reduction internationally were contrary to state drug-control policies; however, since the ongoing neo-liberalization of society, harm reduction and social work have become a vehicle of government regulation.

The concept of harm reduction, or harm minimization, was created to resist and reduce the harms of drug prohibition (Roe, 2005). In the 1980's, harm reduction consisted of activists, social workers, and PWUD illegally distributing needles and syringes to each other in order to curb the spread of HIV and prevent people from dying (Hunt, Albert \& Sanchez, 2010). Needle exchanges operated illegally, defying the law. Public health advocates and epidemiologists have since embraced harm reduction as a strategy to manage risk, primarily the risk of spreading HIV/AIDS (McLean, 2010). Although this brought much needed financial support to needle exchanges, and undoubtedly saved lives, it also took the practice of needle distribution out of the hands of PWUD and put it into the hands of "professionals", creating what has been termed 
"professionalized harm reduction" (White, 2001, p. 449). This co-opted form of harm reduction practice is employed as a way of disciplining PWUD (Fischer, Turnbull, Poland, \& Haydon, 2004).

Different theorists have applied governmentality to harm reduction, drugs and drug users. Miller (2001) and Mugford (1993) charted Foucault's genealogy of the changing movements of regimes of governance from the 'corporal' to 'carceral' to 'risk management'. They related this movement to drug control policies and the increasing of harm reduction services, and made parallels to the movement to neo-liberalism, the downsizing of the state, and downsizing methods of governing. Harm reduction is an effective method of downsizing because it still manages PWUD; however, because it is a supportive service, PWUD evade police surveillance. The police do not enter harm reduction services settings even though they know that the people who access those services are likely to be in possession of illicit substances. The police work of monitoring illegal drug users is transferred to the social workers to monitor the criminal addict, the downsizing of the governing work goes to harm reduction workers and their role in managing the risky drug-users (Miller, 2001). Mugford (1993) claimed that the benefit of harm reduction is that it eliminates the "drugs are bad" moral arguments. As Mugford (1993) wrote, "the rhetoric of drug control, has moved towards a 'risk management' approach whereby 'the moralising enterprise of discipline fades, to be replaced by the management of populations and the 'risks' that populations create" (as cited in Miller, 2001, p. 179). Roe (2005) argues that as harm reduction became a more professional and apolitical field, it no longer advocated against the harms of drug prohibition. Instead professional harm reduction works alongside the criminal justice system in "more 
'progressive' practices of governance [which] coexist alongside more traditional forms of repression (i.e., law enforcement), and indeed can be seen to mask and allow them to continue" (Fischer et al., 2004, p. 358).

The next section will look at how the framework of governmentality has been used to describe harm reduction services. McLean (2011) provided an analysis on needle exchanges and how PWUD govern their injection behaviour by governing themselves, claiming

the discourse of risk that underpins needle exchange posits IDUs as rational subjects who are inevitably interested in preserving their health status through strategies of HIV prevention; it further encourages them to take responsibility for the welfare of others by declining to share injection equipment (McLean, 2010. p. 76).

While Mclean's (2011) research analyzed needle exchange services by interviewing PWUD, she advocated that her work "be supplemented by an ethnography of the concrete practices that occur within needle exchange programs (NEPs), and an analysis of the site-specific discourses that shape them" (p. 72). This research attempts to do just that by focusing on the staff actions and washroom drug use policy.

Moving from governance in needle exchanges to governance in SIS, Fischer et al. (2004) targeted their analysis specifically at SIS as the epitome of 'professional harm reduction' control and surveillance, arguing that while it is never listed as their primary objective, the purpose of SIS is to reduce the public nuisance of drug use. As well, through the SIS intervention, gentrification can occur at a faster rate, providing a singular space to monitor and control PWUD (Fischer et al., 2004). Smith (2016) criticized people 
who work in harm reduction services, needle exchanges, and SIS, as "harm reduction hipsters" (p. 210). Smith (2016) suggested these workers have an "affinity with marginal, lower-class urban populations (including people who use drugs)" (p. 213). According to Smith, they are only interested in harm reduction only because it is edgy and cool.

However, they are not vested in the interests of legalizing drugs or ending homelessness, and thus they perpetuate the governing of PWUD. This leads into the next section, on how governmentality has been used to describe social workers in agencies that are not harm reduction focused.

The theoretical framework of governmentality has been applied to the performance of social work more broadly. Pollack (2010) discussed how social workers perform the role of 'translating' state power to individuals, groups, families, and communities. She looked specifically at how women who were recently released from incarceration experienced state power and how they governed themselves to be seen as less risky when they were released. Pollack (2010) further referenced social workers' position in reinforcing the role of governance onto the women who were released in order to make them conform to the expectations of the law.

Parada (2002) used governmentality to describe the work of child welfare workers and how they implement policies onto the families they work with. Moffatt (1999) used the theory of governmentality to analyze the welfare office to see how the welfare worker is disciplined and disciplines the welfare subject to conform to a specific way of interacting with the state. He saw the welfare office as a site of disciplinary power and highlighted the importance of recognizing the power social workers have to control the health and wellbeing of the people who utilize social services. Moffatt (1999) used 
Foucault to understand power relations, arguing that from the design of the welfare office, to the details on the forms; all of these "technologies" reproduced the surveillance of the welfare recipient. Both Moffatt's (1999) and Parada's (2002) studies will be further examined in the literature review in order to describe how social workers govern service users.

Overall, the theoretical framework of governmentality has been used to explain how people govern themselves and others, how harm reduction has been co-opted by the state to reinforce ways of being, and how harm reduction workers and social workers internalize and reproduce governance of their service users. 


\section{Chapter 3: Literature Review}

This literature review will be divided into different categories. First, this chapter will review literature on PWUD who inject and smoke outside and in public washrooms, to illuminate the problems associated with outdoor drug use and the benefits to injecting in washrooms. The second part will review literature on harm reduction distribution services, PWUD's perception of these services, and the drawbacks of these services. The third part of this chapter will focus on empirical research about social workers. This section will be broken into literature about social workers following of rules more generally, and then will examine literature that specifically studied social workers in harm reduction settings. Finally this literature review will show that while there is plenty of research done on PWUD involvement with harm reduction services, and some research on social worker's governance of their service users, there has been very little research on social workers governance of PWUD in harm reduction distribution agencies. Given that this is a common place for people to use drugs, it is worth exploring.

While there is a large amount of both qualitative and quantitative research on public drug use and space, mostly thanks to the large epidemiological interests in combating HIV/AIDS rates, the regulation and control of space has not been researched as much (Campbell \& Shaw, 2008). Small et al.’s (2007) ethnographic research from Vancouver, BC, specifically analyzed the outdoor injection setting of alleys and interviewed people who were using in those spaces. The possibility of assault, overdose, isolation, and police encounters all heightened the risk and resulted in hurrying and worrying when injecting outdoors (Small et al., 2007). The study provided an in depth intravenous drug user (IDU) perspective of public outdoor setting and all the harms that 
are associated with them. Navarro and Leonard's (2004) quantitative research surveyed 506 people who inject drugs publicly in Ottawa, ON. They found 65\% of survey participants had engaged in public injecting, $41 \%$ had injected in a public washroom, and $34 \%$ had injected in stairwells, abandoned buildings and school yards (Navarro \& Leonard, 2007). Homelessness was the highest factor to predict public injecting, with people who were homeless being seven times more likely to inject in public than people who had housing. The most frequently cited reasons given for public injecting were “convenience”, "privacy”, "safety", "immediacy" and having "no choice”(Navarro \& Leonard, 2007, p. 279). Pearson, Parkin, and Coomber (2011) created a typology of outdoor injecting spaces and noted that outdoor public injecting has many dangers. They also highlighted the importance of washrooms as a best-case scenario for PWUD who are homeless and have limited safe places to use drugs. Business and organization washrooms are often used for drug injecting. In Wolfson-Stofko, Bennett, Elliott, and Curtis's (2017) study of New York City businesses, they found managers of cafes and restaurants who had experienced drug use in their washrooms. Out of 86 business managers of cafes, fast food businesses, and restaurants, $58 \%$ had an encounter with drug use in their washroom in the six months prior to the study (Wolfson-Stofko et al., 2017).

Businesses and organizations have used various methods to deter injection drug use in their public washrooms. Parkin and Coomber (2010) as well as Crabtree, Mercer, Horan, Grant, Tan, and Buxton (2013) completed qualitative research with PWUD to learn about the impact of blue lights on injection drug use in washrooms. They found that generally people enjoyed using the washrooms because of the privacy they created and there was less hurrying and worrying than experienced in outdoor injecting. Blue-lights 
were installed in the washrooms in an attempt to deter drug usage; however, participants reported that they would continue to use drugs in a washroom with blue lights, even though it made it harder to inject and more likely to cause injury (Crabtree et al., 2013). Parkin and Coomber (2010) contended that the regulatory practice of trying to deter drug use in washrooms is a form of symbolic violence. This symbolic violence could apply to any form of discouragement that makes injecting more difficult. They also argued that, "The use of toilets for such purposes [injecting drugs] has been further described as not ideal conditions for injecting purposes, but from an IDU health perspective they do, at least, provide less harmful settings until more viable initiatives become available" (Parken \& Coomber, 2010, p. 636). The next section will look at the literature focusing specifically on harm reduction distribution services.

Harm reduction equipment distribution is a controversial service due to the global war on drugs; there is the moral argument that drugs simply are bad. This perspective does not include a deeper understanding of the pervasiveness of addiction. Harm reduction agencies distribute needles/syringes, cookers, alcohol swabs, sterile water, cotton filters, and tourniquets that are supplies used for safer injecting practices. They also distribute Pyrex glass stems, screens, vinyl mouthpieces, and push sticks for pipes to smoke crack-cocaine, known as safer inhalation supplies. There are 180 locations where harm reduction supplies are distributed in Ontario (OHRDP, 2017). Harm reduction distribution agencies go under many names. Needle exchange is a common term that was more fitting back in the time when there was a strict one-for-one trading policy, where people could not receive new needles without returning used ones. This needle exchange practice is no longer considered best practice. Now, in Ontario, most agencies that 
distribute harm reduction supplies give as many out as people feel that they need, with no requirement to 'exchange' any in return. Harm reduction supplies can be distributed at any number of agencies. The central Ontario Harm Reduction Distribution Program, located in Kingston, Ontario, supplies the equipment to local public health agencies, which then distribute the supplies to their municipal partners (OHRDP, 2017). Thus, shelters, community health centres, drop-in centers, and pharmacies can all be partner agencies that distribute harm reduction supplies.

Harm reduction distribution agencies are a common place for injection drug use to occur. In their study on the appreciation of needle exchanges MacNeil and Pauly (2011) interviewed 33 intravenous drug users and found that needle exchanges were considered safe places that reduced stigma, where PWUD felt respected, and had access to many different services. This would make the washrooms in such harm reduction agencies prime locations to inject or smoke drugs. There have been few thorough research studies that have analyzed the washrooms of harm reduction distribution services specifically. A news report illuminated that people are injecting drugs in a harm reduction agency's washrooms in Ottawa (Metro News, 2014,). Despite evidence that some needle exchanges harshly monitor and restrict their washroom usage (MacLean, 2013) a report published from Victoria, BC by Wallace et al. (2016) found that many PWUD are injecting in washrooms of social services with front-line workers aware that their washrooms are being used as de facto injection sites. The USA-based Harm Reduction Coalition also published anonymous interviews with different needle exchange agency staff who reported to be openly providing support for PWUD to inject in their washrooms (Harm Reduction Coalition, 2013). The support was provided covertly, without explicit 
written policy, walking a fine line between providing service and organizational liability. The interviewees reported a range of service provision, from a 15-minute egg timer check-in, that ensured the service user had not overdosed, to explicit conversations with clients about the quality of drugs they were using and how safe they felt. The interviewees made clear that their funding sources were not aware of these practices, nor were there any explicit policies describing their practices (Harm Reduction Coalition, 2013).

There is clear evidence that the provision of supervised injection services would reduce overdose deaths, reduce the spread of HIV/AIDS, reduce public injecting, and cause no increase in criminal activity (Kerr, Wood, Montaner, \& Tyndall, 2009).

However, until the time comes when SISs are opened, or drugs are decriminalized, front line harm reduction workers can open their agency's washrooms to PWUD as a stop-gap measure to prevent overdose deaths and provide more adequate services to their service users. In many cases, this would require the harm reduction worker to be wilfully ignorant of the drug use occurring in their washrooms, or openly in violation of organizational policies as well as the Controlled Drug and Substances Act. The next section will review the literature on social workers in the harm reduction field. It will begin by exploring how social work and harm reduction have been understood together, then will look at how social workers more generally can perform their role in governing or resisting their power over service users.

As mentioned in Chapter 1, harm reduction practice began as an illegal service of giving needles out to PWUD in order to prevent the spread of HIV (Mclean, 2010). It eventually became legalized as a response to the HIV/AIDS crisis. As public health 
organizations took on the cause of harm reduction, they professionalized it (White, 2001). Since harm reduction has become professionalized it has also become sanitized, and deemed 'amoral' or value free, harm reduction neither endorses drug use, nor condemns it. Miller (2001) argues that this amoral interpretation of harm reduction is incorrect and says, "by not actively addressing the reasons behind current drug policy, harm minimization passively supports the status quo and fails to realistically improve the situation for heroin users" (p.173). White (2001) also argues that the professionalization of harm reduction practice has removed PWUD from the positions of frontline workers, and put in their place well-meaning social workers that do not necessarily have a stake in the shared goal of ending the war on drugs, drug prohibition, homelessness and poverty.

Social workers' involvement and harm reduction practice has been argued as mutually beneficial (Vakharia, \& Little, 2016). Vakharia and Little (2016) argued that both social work and harm reduction share the same values of being client centered and both hold the importance of meeting the client where they are at. This view assumes that, as a social worker, you are not going to shame your client or service user from using substances that are illegal. Despite their advocating for social workers to align themselves with harm reduction, Vakharia and Little (2016) made no mention of resisting the war on drugs and drug prohibition. The authors also did not argue for helping to create safer spaces for people to use drugs. Research on social work practitioners engaging in harm reduction service provision has generally shown favourable perspectives (Mancini \& Wyrick-Waugh, 2013), although 'harm reduction therapy' seems to endorse the amoral perspective of what harm reduction is. Social workers can thus embrace an amoral, professionalized harm reduction practice, which reinforces power over and control by the 
state. As was mentioned before Pollack (2010) referred to the social work role of translating state power to individuals and communities. In the case of harm reduction, the front-line worker, by taking an amoral position, would reinforce the status quo, drugprohibition.

Moffatt (1999) studied how this translation of state power in social work impacted welfare recipients. Moffatt (1999) took the Foucauldian perspective that "power is simply a "certain type of relation between individuals"” (p. 221). He interviewed welfare workers and analyzed the layout of the welfare office and the procedures that the worker performs to illuminate how power operates between the worker and the service user. He argued that the job of the welfare worker is prescribed by the state and is designed to govern the service user. However, according to Moffatt there were opportunities for workers to resist. Workers could refuse to hear of the subversive acts of their clients, and thus allow them to retain more benefits, or the worker could meet with their clients outside of the confines of the interview office, which reduced the power that the welfare office wields. These points of resistance are important to understanding how social workers can both govern and resist within their organizations.

Parada (2007) studied social workers in the field of child welfare and performed an institutional ethnography on child welfare practices analyzing how social workers in child welfare agencies are restricted in their practice by proceduralization and standardization. Like Moffatt (1999), Parada (2007) found that social workers were restricted to perform their role in a prescriptive manner, however there were opportunities to resist. "Once workers have experience with the system, they start to make decisions based on their practice wisdom, rather than simply blindly following the dictates of the 
institutional protocols" (Parada, 2007, p. 49). This experience created an opportunity for the social workers to resist the prescriptive procedures of their organization.

Arnd-Caddigan (2012) studied how clinical social workers navigated the state requirements to use evidence-based practice when providing psychotherapy counselling. She found that in the clinical counselling setting, social workers in the study had freedom to follow the evidence based practices that best aligned with their values, meaning that they did not report to be overly controlled by the government mandated requirements (Arnd-Caddigan, 2012). This study illuminated the other end of social work practice as social workers did not feel as restricted or standardized in how they performed their social work practice. Of course it is worth noting that, even in the freedom of the counselling setting, social workers are still mandated to perform their services in a stateapproved manner.

The next section will focus on research done on social workers and rules; Fine and Teram (2013) interviewed 71 social workers in Ontario, in both front-line and administrative roles. According to them, social workers found covert and overt ways to challenge and resist any moral injustice in the workplace. Fine and Teram (2013) also found that "overt actions are driven by the imagination of better alternatives ... [that] ... do not push for radical changes and are not as risky as covert actions that reject and violate current institutional arrangements" (p. 13). They explained covert action as "resistance with a cost—possibly at the cost of losing one's job if caught—but certainly at the cost of fear of discovery, isolation and condemnation" (Fine \& Teram, 2013, p.14). The authors argued that the neo-liberal policies that continue to try and control the role of social work need to be resisted in order to fight for social justice. With regard to social 
workers in the field of harm reduction, the allowance of drug use to occur in a harm reduction agency will always be covert, as federal law prohibits the allowance of drug use and possession to occur outside of exemption zones. Harm reduction workers who do allow such practices to occur are regulated by their supervisors and co-workers; however, the supervisors must decide how close they monitor their front line staff with respect to these actions.

This literature review began by reviewing research on PWUD in public spaces and washrooms. The review then looked at studies on harm reduction agencies and the possibility of drug use occurring there. Then this literature reviewed social work practice related to harm reduction as well as social work practice more generally and examined how it is regulated. Finally this review looked at how social workers resist translating state power onto their service users. What has not been explored in the literature is how social workers in the harm reduction field employ the rules of their organization, and thus translate the drug-prohibitionist policies from the federal government, or how they resist these federal laws and allow people to use drugs in their washrooms. The research question asks: how front-line harm reduction workers enact the rules of their organization, and thus translate the drug-prohibitionist policies from the federal government onto the service users? As well, how do harm reduction workers resist this federal governance and allow people to use drugs in their washrooms? To answer these questions, an institutional ethnography will be used. 


\section{Chapter 4: Methodology}

In this section, the paper will explain the methodology of institutional ethnography (IE), describe its origin and also discuss the components that make up an IE. This chapter will explain why an IE will be used, look at other examples of IE done more generally, and also specifically describe studies performed in social work. Lastly, this section will explain how IE will be employed in this paper, the specific methods that will be utilized to collect data, and how that data will be analyzed.

"Institutional ethnographers treat people's lived experience of the everyday world as the problematic of an investigation" (Campbell \& Gregor, 2002, p. 46). Institutional ethnography was created by social scientist Dorothy Smith (1987). Smith's original work was important in centering women's experiences in the day-to-day world that they lived in. Smith (1987) argued that research needed to take the standpoint of the women in the everyday world as their central focus for understanding how power relations occur. As she wrote, "From different standpoints different aspects of the ruling apparatus and of class come into view" (p. 107). From these standpoints, what she termed "the problematic character of the everyday world" could be illuminated (Smith, 1987, p. 93).

Through the use of standpoint, observations, interviews, and text, an IE aims to provide "a way of exploring such puzzles and discovering how our activities wherever we are at work $[\ldots]$ are brought under the jurisdiction of the ruling texts of institutional life" (Devault, 2006, p. 297). In an IE, the perspective, or standpoint, is essential in focusing on the power that exists in that one position. For IE in social work the standpoint is the centring of the service user, social worker, or administrator of the institution. The social worker enacts the nature of the 'ruling texts' and decides how they 
enact the texts. "Institutional ethnographies are built from the examination of work processes and study of how they are coordinated, typically through texts and discourses of various sorts" (Devault, 2006, p. 294).

The techniques involved in performing IE will now be described. Observations can be used in IE, either of others or of one's own professional experience in the field (Campbell \& Gregor, 2002). Observation is useful in IE as "the researcher carries a sense of the research into every observational site and will see elements of what is happening that appear to touch on it" (Campbell \& Gregor, 2002, p. 76). Thus, observing with a lens focused on seeing power dynamics is essential to framing the information gathered in other parts of the IE.

Texts can activate ruling relations and create the problematic that is being studied. Texts can be many different things, including policies, posters, signs, and application forms. The analysis of the data gathered in an IE occurs when researchers compare and contrast the observations with the interviews and the text. When these components are combined they can illuminate how power operates in a specific setting at a specific time.

Interviews are used in IE to get an understanding of how people do what they do. This can include asking participants how they enact the policy of their agency, not necessarily how they are 'supposed' to enact the policy (Campbell \& Gregor, 2002). Interviews are integral in learning about the behaviour as well as the justification for this behaviour and the reasoning and logic of the decisions being made.

Analysis is done in IE by creating a map of social relations, for example, mapping a workplace. I did so by taking a particular standpoint to make observations, reading texts then comparing them to the interviews, and combining all of this data together to create a 
map of how an organization operates. The information gathered illuminated what the organizational ruling relations are and how they were understood and enacted by the members of the organization.

This methodology was chosen because it can illuminate how the ruling relations of drug prohibition exist on the front line and the ways that the governance of PWUD occurs in social work. As was explained in the theoretical framework, this research paper uses the concept of governmentality to explain the ways that front line social workers understand and reinforce ruling government relations of drug prohibition. Teghtsoonian (2015) compares governmentality with institutional ethnography to highlight the similarities as well as the contrasts between the two perspectives. They explain that "each brings to this analytic project an interest in understanding the particular mechanisms through which the goals and ambitions of those who rule/govern are taken up by individuals in diverse local sites as their own" (Teghtsoonian, 2015, p. 331). IE is a methodology that works well within the theoretical framework of governmentality, and as IE is based in activist roots of creating 'change from below', it can provide an alternative explanation for front-line workers who break their agency's rules. Nichols (2016) reflects on the importance of using IE as a form of activism in order to find where the resistance is in performing social work. However, governmentality scholars are clear to point out that even in the moments of resistance, governance still occurs, and the idea of being outside of governance is not possible (Teghtsoonian, 2015).

Institutional ethnographies have been used to better understand social work practice. Welsh and Rajah (2015) used an IE to understand how social workers help women that have been recently released from prison. Parada, Barnoff and Coleman 
(2007) performed an IE about child welfare workers and the system's prescriptive policies using interviews text analysis and past practice observation. In the article, Parada, the first author, reflected on his years of experience within the child welfare system as a front-line social worker, and as a supervisor. This reflexive work involved examining the disjunction between the everyday realities of child protection workers and proscribed institutional protocols and statements in the restructured child protection system. "As an institutional insider, Parada was able to investigate the everyday world as it is put together in the practices and activities of actual [social workers]" (Parada, Barnoff \& Coleman, 2007, p. 39-40).

This research interviewed workers that are currently or have formerly worked in front-line harm reduction. A purposive sampling technique was used. This technique allowed the writer to select only those workers who would actually be handing out harm reduction gear. Due to this they had some responsibility to monitor where the service user goes after they receive the gear. This research takes this writer's standpoint of being a former front-line harm reduction social worker. This writer has six years of experience in the field of harm reduction equipment distribution. This writer has worked in drop-in centres, homeless shelters, and public health organizations distributing harm reduction equipment. Recruitment of harm reduction workers occurred through email listservs and personal networks.

Five harm reduction workers were interviewed and asked to describe their interaction with their service users, washroom use policies, as well as the policies for drug use on agency property. Observations of harm reduction agencies were made, and the layout of public space and washroom access in multiple harm reduction agencies was 
recorded. The author observed exactly where the harm reduction room was located in relation to the washroom, in order to understand how surveillance of service users could occur from both harm reduction rooms as well as front-desk reception areas. Photographs were taken of posters or public policies written on the walls in the washrooms.

IE does not have a specific, prescriptive procedure of how to do an analysis (Campbell \& Gregor, 2002). Dorothy Smith (2005) sees the purpose of analysis in an IE as being to create the map of ruling relations within an institution. This is done in order to see how texts mediate the behaviour of workers and influence how they perform their day-to-day tasks that reinforce power dynamics.

The interviews transcripts and texts were coded to find common practices in the signage as well as descriptions of work duties. The common elements of the harm reduction worker practice were grouped and mapped out specifically in the order in which the worker welcomes service users, distributes gear, monitors washroom use, and is influenced by the posters, policies, and by their co-workers. The ruling relations found in those interactions are representative of the larger ruling relations in society that privilege drug prohibition. Finally, the commonalities of the practice were related back to the concepts of governmentality. The next section will describe the findings from the IE that was performed. 


\section{Chapter 5: Findings}

In an IE, there is a search for the problematic in the everyday. The findings below illuminate the day-to-day actions of the harm reduction distribution agencies.

The section will begin with this writer's standpoint of past employment in organizations that distribute harm reduction material, then will go over the text of posters in washrooms, and finally will review findings from interviews with five front line harm reduction workers.

\section{Standpoint}

The standpoint is this writer's six years of experience working in organizations that provide harm reduction equipment. This writer is a white, cisgendered, middle class, able-bodied, heterosexual male. This writer received an undergraduate bachelor degree in psychology at Carleton University in Ottawa, ON. After finishing the undergrad degree this writer worked in homeless shelters, drop-in centres, and on a mobile harm reduction distribution van. In the shelter, there was a clear rule that the residents could receive harm reduction material from staff, however they were required to leave the premises for 30 minutes after receiving this material. The intention of this policy was to limit the opportunity for residents to use the material on site. During Ontario winters, the temperature can go down to -30 degrees Celsius for multiple days. During these cold winter days, staff would tell the shelter residents to leave the premises, however they would not ensure that the residents left, or force them to leave. This resulted in numerous instances where people were found injecting drugs in the washrooms of the shelter. During this writer's time working in a drop-in centre that provided meals, a rule existed that service users could receive harm reduction material only when they were ready to 
leave the drop-in. There was no rule against the service user returning, and in practice, this writer did not strictly monitor people who had been given harm reduction material. There was evidence of drug use in the washroom, but it was rarely considered a problem. In this role, harm reduction was meant to help people use safely. However, by forcing people to inject outside, our organization was pushing our service users to unsafe places. Starting from this standpoint we look to the text of posters and interview staff that have worked in situations similar to those described above.

\section{Observations}

Beginning with observation in agencies, this writer visited the public washrooms of five organizations that distribute harm reduction material in two different urban centres in Ontario and found a variety of types of signs in the different organizations. The layout in each agency was mostly the same. There was a front desk, welcoming space as soon as you walk into the agency. Off to the side was a harm reduction room, or counter, and washrooms were usually located on the same floor. In some cases, the front desk had a view of both the harm reduction room and the washrooms; in other cases the front desk staff would not have a direct view of the washroom. All washrooms had needle disposal boxes, and all had some sort of sign on the wall related to drug use. Some were single stalled gender-neutral washrooms, others had multiple stalls; due to this writer's gender identity, only gender neutral or men's washrooms were entered.

\section{Texts}

The signs in the washrooms were photographed so that the text of the signs could be analyzed. The signs can be divided into three common messages regarding washroom drug use: supportive messages encouraging safety; ambiguous messages encouraging 
cleanliness; and threatening messages discouraging drug use. Some of the signs would contain all three messages. There were no signs that explicitly welcomed people to use drugs in the washroom.

The first of the three types of signs encouraged safety. The encouraging safety messages asked people to not open sharps containers as they may contract infectious diseases, and noted if there was any need for new harm reduction gear, service users could receive it from the front desk. The ambiguous messages were neither supportive nor threatening and mostly requested cleanliness. The ambiguous messages encouraged people to clean up after themselves, putting used needles in the sharps bins and not in the garbage or toilet and asking them to not put other garbage in the sharps bins. The threatening messages can be divided up into three categories, minor, medium, and major threats. The minor threats were explicit signs saying no drug use allowed on premises, the medium threatening messages stated that there was no drug use allowed and that staff monitored the washroom. The major threatening messages contained a warning that people could be barred from services if they were caught using drugs on premises. It is also worth mentioning that there were no messages that threatened that police would be called or charges would be laid for anyone who was caught using on premises.

Because this writer was not able to access the specific policies of harm reduction distribution agencies, these signs will be used as representative of the rules made public. The interviewed subjects were not able to recite the specific policies of their agency regarding the approval or disapproval of drug use. All participants said that it was commonly understood that no drug use was allowed on the premises. Some of the participants also cited the signs in the washroom as representative of the written 
policy. The messages in these signs will serve as the text which the interviews are compared to although the actual agency washrooms visited were not necessarily representative of the organizations where the interviewees were employed.

\section{Interviews}

Five participants responded to this writer's request and fit the criteria of having been currently or formerly employed at an organization that distributes harm reduction equipment and also has public washrooms. This writer initially attempted to recruit only participants who had formal education in social work or social service work. However, due to time constraints and a lack of immediate interest, this writer opened the recruitment criteria to include front line harm reduction workers who have any formal post-secondary education. In order to maintain confidentiality there will be no participant profiles. Due to the nature of workers subverting their agency rules, any disclosure may risk the participant's employment. However, each participant currently, or has in the past, worked at one of 180 needle distribution services in Ontario, and each organization provides services beyond harm reduction gear distribution.

Harm reduction workers described how their agency operated and how they performed their role as harm reduction staff. There was an expectation that people are not allowed to use drugs on premises; however, drug use was happening in their washrooms. If someone was caught using in the washroom they could be asked to leave and potentially be barred from services. If any obvious drug use was occurring, other agency staff often called on harm reduction workers to monitor the washroom and enforce rules Harm reduction workers reported feeling conflicted in this role because the concept of harm reduction means meeting people where they are at, and providing non-judgemental 
services. They also expressed that they were against the war on drugs, and that for many of their clients, the agency's washroom was a much safer place to use drugs.

Harm reduction workers used discretion when enforcing rules and would all try to reduce negative repercussions to PWUD for using on premises. Harm reduction workers encouraged PWUD to use discreetly and would advocate for reduced barring of clients. All harm reduction workers believed that stigma and discrimination heightened the monitoring and surveillance of PWUD. Harm reduction workers also believed in the greater goals of harm reduction to be in social change, decriminalization of drugs, and reducing stigma towards PWUD. The next section will go over these points specifically point by point, providing quotes from the interview participants.

All five participants agreed that both injection drug use as well as smoking drugs was occurring in their agency's washrooms. Most agencies did not have specific rules in place requiring the service users to leave the premises after obtaining harm reduction gear. Although in the cases where people were required to leave, they could come back on the premises almost immediately. The majority of participants felt that their washroom was in some ways the safest place for people to use, given the limited options of injecting outdoors. The reasons given were that there were staff on site who could administer naloxone in case of overdose, and staff would not call the police, noting that the worst action taken would be the service user getting barred from services. Barring for drug use on the premises varies from place to place; usually it would be on a case-by-case basis, ranging from one week to multiple months. All participants knew that drug use was not permitted on their agency property, but not all participants were able to recite specific policies against drug use. 
Participants mentioned that they would like to provide people with a safer place to use; Participant 3 said "if they don't use here, they will use somewhere far less safe" (Participant 3). Participant 4 described other places where people were using, specifically noting "in the back alley in some like dirty place in some place where you're more likely to get arrested or where there isn't someone around if you overdose" (Participant 4). Some participants felt that harm reduction washrooms were the safer place to use. Participant 1 made the point that, "we tell people to use drugs in a safe place, our bathroom is one of the safest places you could get high, and because if something happens we are going to find you and you are going to be okay" (Participant 1).

Participants reported that harm reduction workers are often called on by other staff to monitor the washroom for drug use. Participant 5 discussed the duty to monitor drug use in the washroom, "I feel pressure as I'm duty bound to do that, I'm with the harm reduction program so I usually get called to deal with it more often than other staff" (Participant 5) while Participant 3 said that if non-harm reduction staff "think someone is using, it's like 'oh it's like your client, fucking deal with it, don't let them use here"'(Participant 3). This kind of response influences the harm reduction staff: "I do feel pressure, because if I don't... look like I'm somewhat enforcing some kind of policy around people not using on site, then I could get canned" (Participant 3).

The most common problem reported by participants was not that people were using drugs on premises, but that they were caught using drugs on the premises, meaning they were not using as discreetly as they could have been. Specifically, there were three common situations that were mentioned by all five study participants that would be problematic. The first problem was that the service user makes a mess in the washroom, 
leaving lots of garbage on the floor of the stall that can be seen from outside. The second problem was smoke in the washroom, and the potential for other people to be affected by second-hand smoke. The final problem was that the person using drugs would 'hog the stall' and take up too much time, thus not allowing others to use the toilet.

The mess was described by Participant 4 as "nesting" where a service user would take everything out of their bags, and place it around the stall. There could also be garbage or blood, "they leave blood or leave things all over the bathroom" (Participant 1). Participant 1 also described that the mess was sometimes an example of a need for private spaces if the person is homeless and does not otherwise have a space to change or go through their belongings. There was also mess described as being drug use paraphernalia lying all over the floor, and if the person does not clean it up, then it is seen as disrespectful for the other people who must use the washroom.

The problem of smoking drugs in the washroom was different from injecting as Participant 2 said, injecting is drug use "where there is no telltale evidence of drug use and there's the other one, where there's smoke and there's a scent right" (Participant 2). In the smoking example, participants described how a washroom could be filled with smoke from crack-cocaine or crystal meth, and that second-hand smoke could actually impact people, especially if there was a concern about the impact on parents with children who may use the washroom after someone has created a lot of second-hand smoke.

The last major problem with drug use in the washrooms was that it occupies the washroom stall and other service users are forced to wait to use the washroom. In agencies that had a limited supply of washrooms, there would be complaints if people spent a long time in the washroom. In all three of these scenarios, the main problem was 
not that the person was using drugs, but that the drug using behaviour impacted others in negative ways and that they were all noticeable from outside the stall.

The harm reduction workers interviewed for this study had a number of different methods to reduce the impact on their clients of being barred from services. None of the interviewees enjoyed barring their clients, and some mentioned that they would outright refuse to bar their clients if they caught them using on premises. "If it's up to me I don't punish nobody... no harm no foul, nobody knows," Participant 2 said. While they would still ask the person to leave, they would not apply a barring from services.

Participants stressed that there was an importance of privacy for people who use the washroom. "People need private spaces to do private things" (Participant 4) and "what people do in the privacy of the washroom is up to them you know as long as, you know, you can't tell" (Participant 1). Participant 5 said that "If they keep their business private then no one's going to know what they're doing and they can use the washroom and I would be doing my job and they would be having peaceful and quiet joy within the washroom" (Participant 5). This privacy argument was wilful ignorance, and worked as a useful justification to reduce the amount of monitoring that would occur from other staff. As participant one put it, "truth be told there are times that I know people are going into the washroom to use drugs but again I'm not going to look under the door, you know what I mean, it's not my business what they're doing there” (Participant 1).

When some participants were called on to kick someone out of the washroom for using, they would often encourage the service users to use more discreetly Participant 3 said that they have told service users "if you're using just try to be as short as possible, keep it more discreet" (Participant 3). Other participants reported brainstorming with 
clients on how to use more discreetly: "we would also have a side conversation about how to use safely in spaces when you don't have a safe place to use" (Participant 4). Participant 4 described how they coached someone who was caught smoking drugs in the washroom with strategies to do so more discreetly. They told the client that to prevent the washroom from becoming full of smoke, "exhale into the toilet bowl while flushing." Harm reduction workers would make it clear to the service users that the problem is the mess that people can see; therefore, they would tell people to clean up after they are finished in the washroom. Participant 5 described the problem with the mess is that other people have to use the washroom; "[the mess] it's making other people who are in here, feel very unsafe" (Participant 5).

Some participants reported that when they were challenged by other staff to bar clients for using on the premises, they would create plausible cover stories for their bathroom injection use. Participant 3 said how they would respond to their co-worker, “"you saw a syringe? Oh yeah, they are diabetic, they have insulin" (Participant 3). In these situations, the harm reduction worker creates a cover story for their service user in order to normalize injecting in the washroom and to resist the stigma and the assumption that people are always using drugs in the washroom.

Harm reduction workers advocate for the well-being of their service users and refuse to bar people for drug use. As well, they advocate to supervisors and other staff to not bar people. Participant 4 described how barring service users for using on premises made things worse: "if our work is around community safety and our work is around public health banning practices escalate both of those" (Participant 4). Another participant also claimed that one client who was going to receive a lifetime bar for being 
caught using in the washroom was reduced to a two-month bar due to the worker advocating on the service user's behalf.

As mentioned earlier, numerous participants stated that the agency washroom was the safest place for the person to use. Participant 1 said, "as a harm reduction worker I want you to use drugs in our bathrooms" (Participant 1). In trying to navigate between prohibition policies and allowing people to use, all of the participants mentioned that they are constantly resisting the reproduction of stigma and judgement towards PWUD from other staff at their workplace. Participant 4 described the manner in which other staff would track and monitor the people who used the harm reduction services as a "witch hunt”. Participant 5 said that if a co-worker requests that they check the washroom, they would interrogate the co-worker about the specific reasons why they believed that the person was using, and they would not check the washroom unless there was obvious evidence of drug use. This stigma and discrimination was part of the reason why harm reduction workers had to advocate for and justify their client's private use of the washrooms.

What was clear with all participants was that they felt they were in a role where they were responsible to monitor the washroom for drug use. Four out of the five participants believed the larger goal of harm reduction was to end the war on drugs and that drugs should be de-criminalized. All five participants believed that their agency would benefit from supervised injection and inhalation services. As well they believed that reducing stigma and increasing community development for people who use drugs was important, recognizing that they are part of the community and need to have programs to meaningfully involve them. One such program could be community 
development project that pays PWUD and employs them to be involved in the creation and oversight of new and current harm reduction programs.

The majority of participants argued for the decriminalization of drugs more broadly, with an end to the war on drugs as the end goal of harm reduction. As Participant 3 put it, "Criminalization is the status quo, and just constant pushing against criminalization or not, and when you don't, than you are not doing harm reduction" (Participant 3). Participant 5 described "the end goal of harm reduction is to stop this absolutely tragic, embarrassing, foolish, absolutely wasteful, hurtful, unproductive, useless, and like just embarrassingly unsuccessful war on drugs, we need to end drug prohibition" (Participant 5).

Some of the participants believed the end goal of harm reduction was further than only ending drug prohibition, but also advocated for radical social transformation, As Participant 4 argued, "I say revolution because I think we need to change all those things because I think if we decriminalize drugs we can still exclude people really well and stigmatize people in an institutional way" (Participant 4). This participant was referring to the intersectionality of oppression, and advocated beyond simply decriminalizing drugs in order to end oppression.

The problematic illuminated by the interviewees here is how they navigate the role of being required to make sure people are not using in the washroom with their belief that the washroom is the safest place for people to be using. In order to do this, we see front line harm reduction workers using wilful ignorance and coaching people on how to use discreetly in the washroom. Giving the benefit of the doubt, encouraging privacy and arguing to reduce barring was the defense used by harm reduction workers to fight 
against hyper-surveillance, and co-workers 'witch hunting' service users. Participants argued the opposite to surveillance and monitoring, noting that a large part of their role was building trust and trying to make connections with service users.

Overall the findings from this writer's standpoint, the text of the signs, and interviews of participants, illuminate the contradictory nature of harm reduction equipment distribution. The prohibitory signs in the washrooms provide the harm reduction workers cover to claim that they are performing their job of not allowing people to use drugs in the washrooms. However, this cover is limited if people can tell from the outside that someone is using in the washroom.

The text and interviews confirm the contradiction illuminated in this writer's experiences. The findings illuminate the paradox of workers trying to create a safer environment for their service users, while ensuring that people do not use drugs on premises. The signs in the washrooms are mostly unsupportive and instead discourage drug use. Workers who believe that people should have a space to use drugs navigate this contradiction in their beliefs by remaining wilfully ignorant to the drug use that is occurring, encouraging discreet drug use that it can be justifiably ignored by staff members. 


\section{Chapter 6: Analysis/Discussion}

This chapter will analyze the findings and relate them back to the literature review; then it will frame the findings in Foucault's concept of governmentality; lastly, the chapter will discuss the implications and limitations for the findings. The original research question was asking how front-line harm reduction workers enact the rules of their organization, and thus translate the drug-prohibitionist policies from the federal government onto the service users. It also asked how harm reduction workers resist this federal governance and allow people to use drugs in their washrooms. The institutional ethnography analysis asks "what does it tell me about how this event or setting happens as it does?" (Campbell \& Gregor, 2002, p. 85).

The findings illuminate that harm reduction agencies provide signs to make obvious their policies against drug use on premises; however, the staff are well aware of drug use occurring in the agency settings, usually in the washrooms. In order to remain wilfully ignorant about the drug use, staff must use arguments of privacy to justify their own lack of monitoring of these spaces. The harm reduction workers also use arguments that they are creating safety and managing risk to advocate that their washrooms are the safest option for drug use for many of their service users. However, despite this resistance the harm reduction workers continue to regulate where, when, and how policies are enacted, allowing covert use, but not messiness or smoking. These harm reduction workplaces provide an example of how harm reduction is still a co-opted policy that only provides a half-measure of support, limited in its ability to service its population because it is working within a legal system of drug prohibition. 
This analysis will go on to describe how when harm reduction workers enforce, bend or break the rules, they impact the social work and harm reduction fields, and also participate in neo-liberal governance. In doing so, I am striving to see "how the local course of action is articulated to social relations" (Smith, 1987, p. 155). That is, how do front line workers replicate the larger discriminatory rules and regulations in their day-today work?

It was not surprising that all of the study participants knew that there was drug use occurring in the washroom of their agency. This confirms what Wallace et al., (2016) found when interviewing staff at social service agencies, that each washroom was a de facto injection site. The participants also agreed with what Macneil and Pauly, (2011) found, that harm reduction distribution organizations are considered safer than other spaces to be for a PWUD. Each participant argued the importance of creating a welcoming atmosphere and realized that there are few options for people who are using drugs. As in Moffatt's (1999) findings in the welfare office where workers refused to hear subversive acts, this is similar to the wilful ignorance taken up by harm reduction workers at their agencies. As well, Parada, Barnoff and Coleman (2007) found that workers in child welfare would take the prescriptive governing strategies and make them their own. This is similar to how the harm reduction workers would still enforce the rules in the agency, but also would suggest strategies to PWUD as to how to be more discreet.

The findings show that harm reduction workers monitor drug use in ways that can fall into the categories of reinforcing and resisting drug prohibition. The harm reduction workers interviewed simultaneously enforce rules and resist them in different ways. These findings are in line with Fine and Teram's (2013) perspective that social workers 
covertly resist enforcing rules when they believe there is a 'moral injustice' embedded within those rules. As Fine and Teram (2013) stated "Although covert actions do not change systems, they do affect the lives of individuals who are being 'un-served' by these systems" (p. 13). The wilful ignorance shown by harm reduction workers is a method of covert action, This method of covert action serves the needs of service users who otherwise do not have a place to use drugs. When it was clear that the sharps bins in the washroom were full, there was very little doubt in the minds of the harm reduction workers that drug use was occurring. To advocate for service users who were using in the washroom, they used arguments of privacy to resist barring, and to fight back against other discriminatory and judgemental staff. Fine and Teram (2013) would consider advocacy to resist barring an overt action because it could lead to longer term charges and is not as risky as allowing drug use to continue in the washrooms. Overt actions may not lead to as direct positive outcomes as the covert action.

Nichols (2016) argued that performing an IE creates "conditions for critical consciousness- raising among participants; [inspiring] reflection and action on the part of human service professionals and inform[s] collective efforts to create systemic change"(p.2). The research process itself helps to encourage people within organizations to change their day-to-day behaviour. In the interviews, participants expressed frustration and defeat at the fact that they were forced to remove people for using on the premises. The recent actions in British Colombia, Toronto and most recently, Ottawa, where front line harm reduction workers opened their own overdose prevention site (CBC News, 2017) are evidence of front line workers taking overt action, outside of their organizations, to make the change they described in the interviews. 
Workers resisted enforcing bars on service because they believed in the greater goals of harm reduction, not simply managing risks presented by drug users. They were committed to reducing stigma towards PWUD, and believed in ending drug prohibition and the war on drugs. This greater concern for ending the war on drugs would be in contrast to what Smith (2016) referred to as 'harm reduction hipsters', those who have an affinity to the oppressed but do not share the larger goals of ending the oppression of PWUD. The participants in this study talked strongly about their belief in ending drug prohibition and providing more support to PWUD. Although they are governed by their agency's policy and do not openly allow people to use drugs on premises, harm reduction workers defend their service users from over-surveillance from other employees and argue against harsh barring procedures. The findings also support Roe's (2005) assertion that harm reduction as a field merely works alongside more punitive practices, such as incarceration. The constant wilful ignorance of harm reduction staff is not sufficient to protect everyone who uses harm reduction services, thus showing the limits of professionalized harm reduction in ending the war on drugs. Furthermore, while recognizing the racist origins of drug prohibition, and the intention of controlling and punishing specific racialized and poor communities, harm reduction practice as we see here replicates drug prohibition and thus the racial implications from the war on drugs. Specifically, Black people who use drugs will continue to be targeted by the police and harm reduction equipment distribution organizations still contribute to these harms by not providing a place to use drugs (Cooper, et al., 2016). Racism is further perpetuated in the public sphere. We know anecdotally that the visibility of a Black person using drugs in a 
public place will be judged more harshly than their White, or any lighter skinned counterpart.

\section{Governmentality}

Applying Foucault's framework of governmentality to the findings, we see that harm reduction workers do govern how people use drugs on premises. Harm reduction workers ensure that PWUD use discreetly and covertly so that workers do not have to discipline them. The spatial layout of the harm reduction distribution agencies convey a sense of monitoring. Similar to Moffatt's (1999) analysis of the technologies of surveillance in the welfare office, the layout of harm reduction agencies had the harm reduction office within view of the washroom. This circumstance, whether intentional or not, implied a monitoring of the washroom by harm reduction staff. The harm reduction workers themselves were governed by their employment responsibilities; they feel as though they must make sure people are not using overtly in the washroom. These workers resist this hyper-monitoring role by using wilful ignorance and championing service-userprivacy in order to reduce the monitoring of the washroom by other staff. The coaching of PWUD on how to circumvent the rules reduces the negative impact of prohibition, as represented by barring, on their service users.

With regard to governmentality and neo-liberalism, the perspective from the washroom posters, as well as the interviews, illuminates that the visibility of drug use is what is governed specifically. Harm reduction workers perform a regulatory role, thrust on them by their co-workers and their own sense of 'being a good staff member' determining who is the 'good drug user' and who is the user who makes a mess or smokes. The harm reduction distribution agency is dealing with a paradox where they tell 
their service users to manage their own risk by following safer drug use practices; however, when it comes to the safer practice of using in an agency washroom, their signs make clear that PWUD are not welcome to practice safely there. If they do attempt to practice safely they must be as discreet and as secretive as possible, which goes against one of the supposedly fundamental principles of harm reduction specifically 'meeting the person where they are at' (Vakharia \& Little, 2016). While some of the staff members claim to not be regulating the drug use itself, arguing that they only engage in regulatory practices when the drug use impacts others, they are still regulating the mess and the smoke. These two elements being a problem adds another layer to the already risk focused behaviour maintenance that governs harm reduction practice. While this lends support to Mugford's (1993) analysis of harm reduction being another form of risk management, wherein the harm reduction workers manage the risk of other people and staff being exposed to drug use. While the harm reduction workers interviewed in this study believed in the larger goals of ending drug prohibition, they felt pressure from coworkers, as well as from themselves, to perform their job of monitoring the risks that their service users create (i.e., the mess and smoke). Each staff member worked hard to resist the assumption that people were using drugs in the washrooms, and would advocate for little to no consequences for people caught using drugs on the premises. Although they resisted, they jeopardized their employment and constantly navigated between upholding their values and seeking ways to do so that did not risk their employment.

The professionalized harm reduction worker is still translating the power from the federal government, embodied in the Controlled Drug and Substances Act (CDSA), to the PWUD on the front line. Fisher et al. (2004) referred to harm reduction services as more 
"progressive practices of governance [which] coexist alongside more traditional forms of repression" (p. 358). This seems to be so, given the findings that barring can still occur if people repeatedly are caught using drugs on premises. Although these participants used these techniques covertly to resist, the fact that they often had to defend their clients against co-workers who were not willing to give the benefit of the doubt, means that it is likely in many organizations that distribute harm reduction material that they are punishing people who use on premises.

\section{Implications}

Although there are multiple legal supervised injection services likely to be opened in Ontario in the upcoming months, the application process and time it takes to open these services is lengthy. Any changes to end drug-prohibition need to be prioritized in order to reduce the larger problems of overdose death, violence, and discrimination caused by the war on drugs. The activists who have opened pop-up overdose prevention sites are paving the way forward towards ending drug prohibition by creating more spaces where law-enforcement does not operate. Until drugs are legalized there are practical solutions that current harm reduction agencies could employ to make it easier for PWUD to be discreet while using drugs in their washrooms. The signs in the washroom, as they are written were a necessary response to the pressure of enforcing drug prohibition in the agencies, however, according to the harm reduction workers interviewed, to be more accurate, the signs would encourage clean, discreet, and quite drug use. To address the problem of visible mess on the floor, agencies could install shelves in the washroom stalls. This could be justified in Ontario as simply a shelf for people to place their winter gloves, or other seasonal clothing, while using the washroom. 
To address smoking in the washroom, more powerful exhaust fans can be installed to evacuate smoke quicker. This can be justified by arguing, for health reasons, to prevent mould and reduce unpleasant smells. To address the problem of taking up too much time in the washroom, expanding public washroom access, to include more stalls could be a solution. This may be the most expensive/hardest adjustment to make; however, if there is any way to open up more staff washrooms, or washrooms on separate floors of an agency to accommodate these longer time usage needs, it could be done inexpensively.

More research is needed on social work practice in harm reduction and the challenges of working in these supportive environments that are limited by federal policies. As well, research needs to include an examination into the growing phenomenon of 'peer workers', being those who have experience with drug use, as this characteristic is becoming more common in harm reduction services. This would seemingly be a movement away from professionalizing harm reduction practice, however until drugs are decriminalized, it could simply result in peer workers who are under the same contextual obligations as the current harm reduction employees. In doing so, we might see further co-optation of harm reduction, with peer workers translating state policies onto PWUD, who are their fellow peers. The implications of this research for policy would be that the criminalization of drugs creates the circumstances where harm reduction workers are forced to regulate the space of their agency. Each individual harm reduction distribution agency should receive a federal exemption for drug laws in order for these organizations to provide appropriate services to their clients. 


\section{Anti-oppressive practice}

Given the racist, classist, gendered, oppressive nature of the war on drugs and drug prohibition, there has been a disproportionate disadvantage to people who are Black, Indigenous, People of Colour, Trans-gendered, Pan-sexual, female, disabled, poor, homeless and non-citizens (White, 2001). As Kimberlé Crenshaw (1991) described, different oppressions intersect in a manner that has different material impact, as well as different experiences of stigma and discrimination, and a disproportionate criminalization of racialized groups. Khenti (2014) illuminates the necessity for harm reduction workers to push the boundaries on service provision, ignoring use on premises to prevent this criminalization from continuing. Anti-oppressive practice would encourage these small steps that could result in real material benefits to PWUD that also have intersecting identity locations.

\section{Limitations and Strengths}

This study is limited in a variety of ways. The small sample size limited how many perspectives are included and the information could be different at other harm reduction workplaces. A larger sample size may yield different results that may or may not be so politically supportive of ending drug criminalization. Having a greater number of participants would likely find harm reduction workers who themselves monitor the washroom strictly. The lack of all participants having social work, or social service worker educational backgrounds limits the understanding if social work education would have played a role in the worker's actions. The recruitment of participants through this writer's networks and snowballing method likely provided a skewed sample of harm reduction workers who are more likely to be social justice advocates and would 
potentially feel more comfortable being wilfully ignorant to drug use on their agency premises. This is because this writer has done past work in advocacy for increased services, including supervised injection services as well as advocated for an end to the war on drugs. The organizations through which participants were recruited are attended by harm reduction workers with similar values. Also, the research may be quite different in an urban setting compared to harm reduction programs in rural settings where there would likely be less visible homelessness, thus lower rates of public drug use.

The strengths of the study are its originality. There are many studies that have interviewed PWUD and their experiences injecting in public and semi-public spaces, but there are few studies that have researched the harm reduction distribution agencies themselves to explore the common practice of injection drug use on premises. Another strength is the exposure of a grey area in harm reduction that allows for subversion and resistance. This is invaluable to future harm reduction workers in illuminating how resistance is possible within their agency, and how they might go about providing important, de-stigmatized service provision to some of the most marginalized service users. 


\section{Chapter 7: Conclusion}

This research attempted to map how frontline harm reduction workers govern the space that they work in, and how they understand their roles and the larger goals of harm reduction and drug prohibition. It used institutional ethnography to look at how the policies affect the practice of every-day operation of harm reduction services. The theoretical framework of Michel Foucault was used, specifically governmentality, to understand how front-line harm reduction workers are translating state policies as well as circumventing those policies in their day-to-day work. The literature review showcased the reality of public drug use, washroom drug use, and social worker resistance. The findings illuminate how front-line harm reduction workers are forced to perform prohibition inherently in their jobs, translating the CDSA into their community agency. This occurs through the signage in washrooms discouraging use and the discriminatory practices of some co-workers. The harm reduction workers resist this policy by being wilfully ignorant, refusing to bar service users, and encouraging discreet drug use. The war on drugs intersects with many different forms of oppression, from capitalism, racism, hetero-patriarchy. While ending the war on drugs will not end these other oppressive systems, it may limit how disproportionally racialized and poor communities are affected by drug's criminalization. Ending drug prohibition and resisting the war on drugs is absolutely necessary in ending the suffering of people who use drugs. Ending poverty and homelessness would help to create spaces of support and safety. The dreams of the harm reduction workers interviewed of social transformation, revolution and an end to repression of all sorts illuminate the potential for social change through advocacy and resistance. 


\section{References}

Briggs, D., Rhodes, T., Marks, D., Kimber, J., Holloway, G., \& Jones, S. (2009). Injecting drug use and unstable housing: Scope for structural interventions in harm reduction, Drugs: Education, Prevention and Policy, 16(5), 436-450. https://doi.org/10.1080/09687630802697685

Campbell \& Gregor (2002) Mapping social relations: A primer in doing institutional ethnography. Aurora, ON: Garamond Press.

Campbell, N. D., \& Shaw, S. J. (2008). Incitements to discourse: Illicit drugs, harm reduction, and the production of ethnographic subjects. Cultural Anthropology, 23(4), 688-717. https://doi.org/10.1111/j.1548-1360.2008.00023.x

CBC News (2017, August 25). Pop-up drug use site set up in Raphael Burnet Park. CBC News Ottawa. Retrieved from: http://www.cbc.ca/news/canada/ottawa/ottawa-drugoverdose-prevention-location-1.4262506

Clifford, P. R. (1992). Drug use, drug prohibition and minority communities. The Journal of Primary Prevention, 12, 303-316. https://doi.org/10.1007/BF01325177

Cooper, H. L. F., Linton, S., Kelley, M. E., Ross, Z., Wolfe, M. E., Chen, Y. T., ... Kuo, I. (2016). Racialized risk environments in a large sample of people who inject drugs in the United States. International Journal of Drug Policy, 27, 43-55. https://doi.org/10.1016/j.drugpo.2015.07.015

Controlled Drugs and Substances Act, SC (1996, c 19). Retrieved from: http://canlii.ca/t/52wl7. Retrieved on 2017-04-02. 
Crabtree, A., Mercer, G., Horan, R., Grant, S., Tan, T., \& Buxton, J. A. (2013). A qualitative study of the perceived effects of blue lights in washrooms on people who use injection drugs. Harm Reduction Journal, 10(22), 1-8. https://doi.org/10.1186/1477-7517-10-22

Crenshaw, K. (1991). Mapping the margins: Intersectionality, identity politics, and violence against women of color. Stanford Law Review, 43(6), 1241-1299. https://doi.org/10.2307/1229039

CTVNews.ca Staff (2017, August 14). Unsanctioned pop-up site opens in Toronto. CTV News. Retrieved from: http://www.ctvnews.ca/canada/unsanctioned-pop-up-safeinjection-site-opens-in-toronto-1.3544860

Devault, M. L. (2006). Introduction: What is institutional ethnography? Social Problems, 53(3), 294-298. https://doi.org/10.1525/sp.2006.53.3.294

Duffy, A. (2016, April 8). Ottawa must decide whether it wants a safe injection site: Provincial health minister. Ottawa Citizen. Retrieved from http://ottawacitizen.com/news/local-news/ottawa-must-decide-whether-it-wants-asafe-injection-site-provincial-health-minister

Enns, E. A., Zaric, G. S., Strike, C. J., Jairam, J. A., Kolla, G., \& Bayoumi, A. M. (2016). Potential cost-effectiveness of supervised injection facilities in Toronto and Ottawa, Canada. Addiction, 111(3), 475-489. https://doi.org/10.1111/add.13195

Fine, M., \& Teram, E. (2013). Overt and covert ways of responding to moral injustices in social work practice: Heroes and mild-mannered social work bipeds. British Journal of Social Work, 43(7), 1312-1329. https://doi.org/10.1093/bjsw/bcs056 
Fischer, B., Turnbull, S., Poland, B., \& Haydon, E. (2004). Drug use, risk and urban order: Examining supervised injection sites (SISs) as "governmentality." International Journal of Drug Policy, 15(5-6), 357-365. https://doi.org/10.1016/j.drugpo.2004.04.002

Foucault, M. (1991) Governmentality. In G. Burchell, C. Gordon \& P. Miller (Eds.), The Foucault effect: Studies in governmentality with two lectures by and an interview with Michel Foucault (pp. 87-104). Chicago, IL: The University of Chicago Press.

Friedman, S. R. (1998). The political economy of drug-user scapegoating - and the philosophy and politics of resistance. Drugs: Education, Prevention, and Policy, 5(1), 15-32. https://doi.org/doi:10.3109/09687639809035768

Harm Reduction Coalition (2013, April 18) Bathroom etiquette: Injecting at the needle exchange part $1 \&$ 2. Harm Reduction Coalition's Podcast. Podcast retrieved from: https://www.mixcloud.com/harmreductioncoalitionspodcast/bathroom-etiquetteinjecting-at-the-exchange-part-1/

Hunt, N., Albert, E., \& Sánchez, V. M. (2010). User involvement and user organising in harm reduction. In T. Rhodes \& D. Hedrich (Eds.), Harm reduction: Evidence, impacts and challenges (pp. 333-354). Lisbon, Portugal: European Monitoring Centre for Drugs and Drug Addiction Retrieved from http://www.emcdda.europa.eu/publications/monographs/harm-reduction

Kerr, T., Wood, E., Montaner, J., \& Tyndall, M. (2009). Findings from the evaluation of Vancouver's Pilot Medically Supervised Safer Injecting Facility - Insite. Vancouver, BC. British Columbia Centre for Excellence in HIV/AIDS. Retrieved from: http://www.bccsu.ca/wp-content/uploads/2016/10/insite_report-eng.pdf 
Khenti, A. (2014). The Canadian war on drugs: Structural violence and unequal treatment of Black Canadians. International Journal of Drug Policy, 25(2), 190-195. https://doi.org/10.1016/j.drugpo.2013.12.001.

Little, J., \& Franskoviak, P. (2010). So glad you came! Harm reduction therapy in community settings. Journal of Clinical Psychology, 66(2), 175-188. https://doi.org/10.1002/jclp.20673

Macneil, J., \& Pauly, B. (2011). Needle exchange as a safe haven in an unsafe world. Drug and Alcohol Review, 30(1), 26-32. https://doi.org/10.1111/j.14653362.2010.00188.x

Mancini, M. A., \& Wyrick-Waugh, W. (2013). Consumer and practitioner perceptions of the harm reduction approach in a community mental health setting. Community Mental Health Journal, 49(1), 14-24. https://doi.org/10.1007/s10597-011-9451-4

McLean, K. (2011). The biopolitics of needle exchange in the United States. Critical Public Health, 21(1), 71-79. https://doi.org/10.1080/09581591003653124

McLean, K. (2013). Reducing risk, producing order: The surprisingly disciplinary world of needle exchange. Contemporary Drug Problems, 40, 415-445. https://doi.org/10.1177/009145091304000306

McKeown, D. (2016). Staff report for action on supervised injection. Toronto, ON: City of Toronto. Retrieved from: http://www.toronto.ca/legdocs/mmis/2016/hl/bgrd/backgroundfile-90901.pdf 
Metro News (2014, October, 9). Ottawa AIDS group's washroom being used as injection site, volunteers complain. Ottawa Metro. Retrieved from: http://www.metronews.ca/news/ottawa/2014/10/09/ottawa-aids-groups-washroombeing-used-as-injection-site-volunteers-complain.html

Miron, J. A., \& Zwiebel, J. (1995). The economic case against drug prohibition. Journal of Economic Perspectives, 9(4), 175-192.

Miller, P. G. (2001). A critical review of the harm minimization ideology in Australia. Critical Public Health, 11(2), 167-178. https://doi.org/10.1080/09581590123457

Moffatt, K. (1999). Surveillance and government of the welfare recipient. In A. Chambon, A. Irving, \& L. Epstein (Eds.), Reading Foucault for social work (pp. 219-246). New York, NY: Columbia University Press.

Moore, D. (2007) Criminal artefacts: Governing drugs and users. Vancouver, BC: UBC Press.

Mugford, S. (1993). Social change and the control of psychotropic drugs_-risk management, harm reduction and "postmodernity." Drug and Alcohol Review, 12, 369-375. https://doi.org/10.1080/09595239300185461

Murray, M. (2017, March 28). Somerset West Community Health Centre moves forward with injection site. Ottawa Community News. Retrieved from: https://www.ottawacommunitynews.com/news-story/7212442-somerset-westcommunity-health-centre-moves-forward-with-injection-site/

Nichols, N. (2016). Investigating the social relations of human service provision: Institutional ethnography and activism. Journal of Comparative Social Work, 11(1), $1-26$. 
O'Malley, P., \& Valverde, M. (2004). Pleasure, freedom and drugs: The uses of 'pleasure' in liberal governance of drug and alcohol consumption. Sociology, 38(1), 25-42. https://doi.org/10.1177/0038038504039359

Ontario Harm Reduction Distribution Program (2017) Needle syringe programs. OHRDP. Kingston, ON. Retrieved from http://www.ohrdp.ca/about-us/needleexchange/

Parada, H. (2002). The restructuring of the child welfare system in Ontario: A study in the social organization of knowledge. (Doctoral dissertation). University of Toronto, Toronto, Canada.

Parada, H., Barnoff, L., \& Coleman, B. (2007). Negotiating "professional agency": Social work and decision-making within the Ontario child welfare system. Journal of Sociology \& Social Welfare, 34(4), 35-56. Retrieved from http://libproxy.wustl.edu/login?url=http://search.ebscohost.com/login.aspx?direct=tr ue $\& \mathrm{db}=\mathrm{a} 9 \mathrm{~h} \& \mathrm{AN}=27449092 \&$ site $=$ ehost-live $\&$ scope $=$ site

Parkin, S., \& Coomber, R. (2010). Fluorescent blue lights, injecting drug use and related health risk in public conveniences: Findings from a qualitative study of microinjecting environments. Health and Place, 16(4), 629-637. https://doi.org/10.1016/j.healthplace.2010.01.007

Pearson, M., Parkin, S., \& Coomber, R. (2011). Generalizing applied qualitative research on harm reduction: The example of a public injecting typology. Contemporary Drug Problems, 38, 61-91. 
Pollack, S. (2010). Labelling clients "risky": Social work and the neo-liberal welfare state. British Journal of Social Work, 40(4), 1263-1278. https://doi.org/10.1093/bjsw/bcn079

Powell, J. L. (2012). Social work, power and performativity. China Journal of Social Work, 5(1), 67-79. https://doi.org/10.1080/17525098.2012.656364

Roe, G. (2005). Harm reduction as paradigm: Is better than bad good enough? The origins of harm reduction. Critical Public Health, 15(3), 243-250. https://doi.org/10.1080/09581590500372188

Rose, N., O’Malley, P., \& Valverde, M. (2006). Governmentality. Annual Review of Law and Social Science, 2(1), 83-104. https://doi.org/10.1146/annurev.lawsocsci.2.081805.105900

Smith, C. B. R. (2016). Harm reduction hipsters and the gentrification of public health. In C. B. R. Smith \& Z. Marshall (Eds.), Critical approaches to harm reduction (pp. 209-229). New York, NY: Nova Science Publishers, Inc.

Smith, D. (1987). The everyday world as problematic: A feminist sociology. Boston, MA: Northeastern University Press.

Smith, D. E. (2005). Institutional ethnography: A sociology for people. Lanham, MD: AltaMira Press.

Teghtsoonian, K. (2015). Methods, discourse, activism: Comparing institutional ethnography and governmentality. Critical Policy Studies, 1(1), 1-18. https://doi.org/10.1080/19460171.2015.1050426 
Vakharia, S. P., \& Little, J. (2016). Starting where the client is: Harm reduction guidelines for clinical social work practice. Clinical Social Work Journal, 45(1), 6576. https://doi.org/10.1007/s10615-016-0584-3

Wallace, B., Pauly, B., Barber, K., Vallance, K., Patterson, J., \& Stockwell, T. (2016). Every washroom: De facto consumption sites in the epicenter of an overdose public health emergency, Centre for Addiction Research British Columbia Bulletin, 15 (August), 1-8.

Welsh, M., \& Rajah, V. (2014). Rendering invisible punishments visible: Using institutional ethnography in feminist criminology. Feminist Criminology, 9(4), 323343. https://doi.org/10.1177/1557085114524616

White, C. L. (2001). Beyond professional harm reduction: The empowerment of multiply-marginalized illicit drug users to engage in a politics of solidarity towards ending the war on illicit drug users. Drug and Alcohol Review, 20(4), 449-458. https://doi.org/Doi 10.1080/09595230120092742

Wolfson-Stofko, B., Bennett, A. S., Elliott, L., \& Curtis, R. (2017). Drug use in business bathrooms: An exploratory study of manager encounters in New York City. International Journal of Drug Policy, 39, 69-77. https://doi.org/10.1016/j.drugpo.2016.08.014 